\title{
Optimal designs of electric vehicles for long-range mobility
}

\author{
Zlatina Dimitrova ${ }^{1, *}$ \\ ${ }^{1}$ PSA Groupe, Research and Innovation Department, 78943 Vélizy-Villacoublay, France
}

\begin{abstract}
This paper introduces the major priorities of the automotive industry of reducing energy consumption and emissions of the passenger cars of the future and of delivering an efficient mobility service for customers. The number of electric vehicles and hybrid electric vehicles is increasing in the mobility market. The problems of the range and the energy storage of the vehicle on board are important. This paper studies the energy system of electric vehicles for different ranges and mobility usages. A multi-objective optimization method is applied to estimate the optimal vehicle energy system designs for urban mobility and for long way electric mobility $(>500 \mathrm{~km}$ ). Optimal designs considering technical, economic and environmental criteria are presented. The relations between the vehicle ranges and the energy densities of high voltage batteries are illustrated. The boundary of the system is extended to the vehicles and the grid system, including the charging infrastructure. The vehicle energy systems and recharging needs are analysed for a range of $500 \mathrm{~km}$ on electric drive.
\end{abstract}

\section{Introduction}

The electrification of vehicles is driven by the trend for decarbonisation and emission reduction of road transport.

Around 2030, electric vehicles are predicted to increase their market penetration and to bring evolution concerning the main technologies for energy storage and conversion, powertrain components and energy management [1]. The industrialisation of those components on a high scale and volume reduces the cost of the electrification and the democratisation of the electrification on all vehicle segments. Hybrid electric vehicles with different level of hybridisation are proposed for several vehicle segments. They are designed for urban and peri-urban drives, and allow for zero emissions drives from thank-to-wheels perspective for $25 \mathrm{~km}$ or $50 \mathrm{~km}$. Hybrid electric vehicles with "zero emission vehicle" modes are supported by incentives for circulation in big cities centres. According to the ERTRAC Report [1] it is possible to distinguish between two types of electric vehicles: user friendly affordable vehicles and high performance electric vehicles. The first category will develop in small and middle segments $(\mathrm{A} / \mathrm{B} / \mathrm{C})$ and they represent a more optimized range/cost solution enabling a very big market penetration with considerable impact on greenhouse emissions reduction. The ranges of these vehicles are adapted for ranges of $200 \mathrm{~km}$ and are suited for urban and sub-urban use. The major challenge is to achieve significant cost reduction of the battery and the propulsion system components. The introduction of these vehicles is related to the support of the governmental policies (transportation energy taxes, city centre driving), the infrastructure deployment and the cost of electricity. High performances electric vehicles are deployed in the $\mathrm{C} / \mathrm{D} / \mathrm{E}$ segments. They will maximize the range in the performances offering at least $600 \mathrm{~km}$ on a single charge. The cost of these vehicles is high because of the high battery capacity on board. The cell energy density needs to be improved to allow for the deployment of these vehicles. The significant battery capacity can be rapidly recharged with high power chargers. These cars are designed for long distances, on the highways and their deployment is related to the deployment of the high speed chargers infrastructure all along the highways.

Customers' expectations and considerations for buying electrified vehicles are acceptable prices, range, reliability, durability and re-sale value similar to conventional vehicles. Some advantages may also be achievable through synergies of the electrification with the connectivity and the automation of the vehicles. This will provide benefits for the users through easy access to the charging infrastructure, optimization of the traffic and minimization of energy consumption. Charging is a crucial topic for the success of electrification. Purely electric vehicles are pushed to compete with internal combustion engine vehicles one-on-one, where refilling takes place around once every week. With the right mix of infrastructure, electric vehicles could compete with vehicles powered by internal combustion engines, but with the added dimension of the refilling comfort. Daily e-charging would mean that drivers never have to stop at filling stations, except at rapid charging stations for long way drives. Information and connectivity solutions that inform, in real time, the drivers about the availability and distribution of the charging infrastructure, including the possibility to book and pay for charge points in different places, is an important part of the solution. Combined with fast, i.e. high power charging capacities, pure electric vehicles would be able to serve long range needs.

\footnotetext{
${ }^{*}$ Corresponding author: zlatina.dimitrova@mpsa.com
} 
Zenginis and al. propose in [2] the waiting time in the queue of the customers for recharging their batteries. The model considers the stochastic recharging of the battery capacities and the class of the vehicles. Furthermore, a charging strategy is proposed according to which the drivers are motivated to limit their energy demands. Karakitsios and al. introduce in [3] a methodology to analyse the impact of the fast inductive charging technologies to the grid. Levinson and al. [4] explore the potential of public charging infrastructure to spur US battery electric vehicle. They used market analysis and simulations. Zhang and al. develop in [5] a multi-period flow refuelling location problem for electric vehicles (EVs) and charging infrastructure. The optimization model determines the optimal location of chargers for every station. Sun and al. explore in [6] the choice of the users to fast charging of battery electric vehicles as a function of the available charging stations and the distance between them, in Japan. Su and Sioshansi develop in [7] a model to optimize the location of public fast charging stations for electric vehicles (EVs). They use a stochastic flow-capturing location model to solve the uncertainty about where EV charging demands appear. Schroeder and Traber provide in [8] the business case of fast charging technology in a case study for Germany. They estimated that the Return on Investment (ROI) of a public fast charging station constitutes the main contribution. The general EV adoption rate is estimated to be the main risk factor for investment in public charging infrastructure.

The novelty of the present study is the application of a systematic multi-objective optimization methodology for defining the optimal design and operation parameters of the electric vehicle energy system. The optimization considers optimal vehicle energy systems designs, in terms of technical, economic and environmental criteria. This three-objective optimization is also called environomic optimization [9], [10]. The methods and techniques of analysing, improving and optimizing energy systems have to deal not only with energy consumption and economics, but also with environmental impact. The multi-objective environomic optimization includes all these activities.

\section{Methodology}

The developed methodology combines flowsheeting models of technologies, energy integration techniques, evaluation of the economics and life cycle assessment in a computational platform. Multi- objective optimization techniques are used to explore the superstructure possibilities and to find the optimal design solution. The master optimization is done by using a genetic algorithm and mixed integer nonlinear programming. Such an integrated approach is innovative as compared to the traditional heuristic design engineering method, based on iterations of designs and their cost evaluation. Fig. 1 presents the generic computational framework for environomic design of a vehicle energy system. The superstructure contains a vehicle simulation model, with dynamic layouts. The cost equations are implemented in the model of economics. A Genetic algorithm based on optimizer is used. The set of decision variables includes the types and the size of powertrain components. The master optimization is solved by an evolutionary algorithm with 3 objectives: the minimization of the electric consumption, the minimization of the investment cost and the environmental impact of the technologies (Fig.1). The multi-objective optimization results converge to the Pareto frontier curve. In this study energy integration is not applied.

\subsection{Electric vehicle dynamic model}

Electric vehicles are characterized by a powertrain that stores and converts electric energy. This energy conversion chain consists of a battery (or another electricity storage system) and the electric motor with its controller. The size of the high voltage battery and its density affects directly the autonomy of electric vehicles. Permanent magnets synchronous machines are mostly used as traction motors. The peak power ranges are from 50 to $80 \mathrm{~kW}$. Lithium-ion battery energy typically ranges from 15 to $25 \mathrm{kWh}$. The top speed and range of such cars reaches $135 \mathrm{~km} / \mathrm{h}$ and $160 \mathrm{~km}$ autonomy on combined driving cycles. Electric consumption is measured in $\mathrm{kWh} / 100 \mathrm{~km}$ or $\mathrm{Wh} / \mathrm{km}$. The electric consumption depends on the efficiency of the powertrain components: the electric machine, the battery and the transmission. The electric machine acts in motor and generator mode and

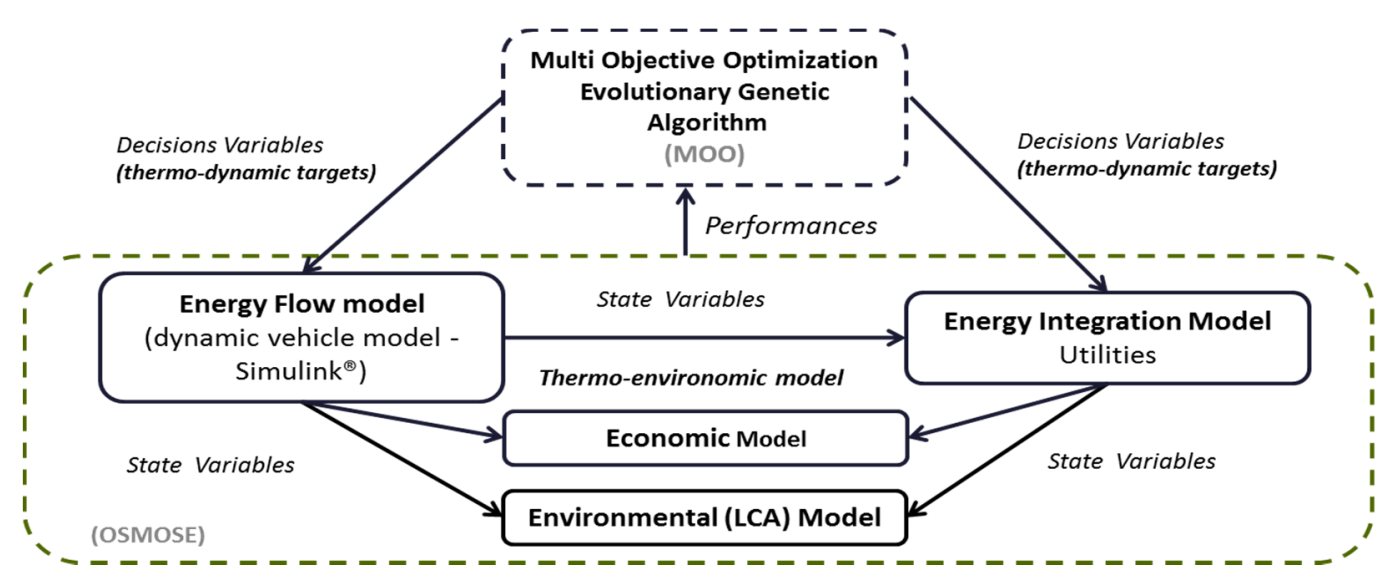

Fig. 1. Computational framework of environomic optimization. 
during braking the kinetic energy is recovered and stored in the high voltage battery as electricity. Typical values of the energy consumption of recent electric vehicles are 10$15 \mathrm{kWh} / 100 \mathrm{~km}$, characterized on combined driving cycles. The quasi-static approach is used for the modelling. The voltage and the current are the constituents ("power factors") of electric power. Since the former can only have positive values, it plays an analogous role to that of speed in mechanical power. The current can switch direction to represent both power flows from (positive current) or to the storage system (negative current). The negative current occurs during the regenerative braking. Thus, current is the electric analogue of torque and force. Figure 2 lists the causality of power factors of an electric vehicle.

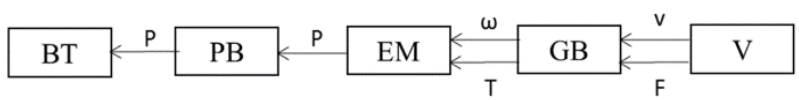

Fig. 2. Electric vehicle quasi-static model: BT - battery, PB power link, EM - electric machine, GB - gear box, V- vehicle.

The main characteristics of the electric vehicle model are given in Table 1.

Table 1. Electric vehicle main characteristics [11].

\begin{tabular}{|c|c|c|}
\hline Sub-System & Characteristics & Value \\
\hline Vehicle & Nominal mass, $\mathrm{kg}$ & 1195 \\
\hline Gear box & IVT efficiency, - & 0,9 \\
\hline Energy & Electricity & \\
\hline Electric motor & $P_{E M}, \mathrm{~kW}$ & 125 \\
\hline Battery & Type & Li-ion \\
\hline & Capacity, $\mathrm{kWh}$ & 19 \\
\hline
\end{tabular}

\subsection{Vehicle cost model}

The size and efficiency of energy converters and energy storage devices impact the economic evaluation of the vehicle. The cost is calculated for every run. The economic equations of the components come from the literature and are related to the size of the components. Table 2 presents the cost equations.

Table 2. Equations for the economic model.

\begin{tabular}{|l|lr|}
\hline \multicolumn{1}{|c|}{ Components } & \multicolumn{1}{|c|}{ Cost, $€$} \\
\hline Electric motor [12] & $30 € / \mathrm{kW} \times P_{E M}, \mathrm{~kW}$ \\
\hline Thermal engine [12] & $15 € / \mathrm{kW} \times P_{T E}, \mathrm{~kW}$ \\
\hline Battery [12] & $\begin{array}{l}600 € / \mathrm{kWh} \times 0,2477 \times \\
\log (\text { battery } \\
+0,5 p e c i f i \text { mass }\end{array}$ \\
\hline bat_type $)$ \\
\hline Supercapacitor [12] & $15 € / \mathrm{kW} \times P_{\text {batt }}, \mathrm{kWh}, \mathrm{kW}$ \\
\hline $\begin{array}{l}\text { Nominal cost } \\
\text { (car shell) }\end{array}$ & $\begin{array}{l}\text { 17,3 } \\
\text { Elear_shell_mass } \mathrm{kg}- \\
3905,4 €\end{array}$ \\
\hline Electricity household [12] & $0,14269 € / \mathrm{kWh}$ \\
\hline Diesel [12] & $1,451 € / \mathrm{L}$ \\
\hline
\end{tabular}

The cost of the electric machine includes the cost of the power unit. The battery cost is sensitive to the battery type and the energy storage capability of the material. The nominal cost represents the vehicle shell cost, without the powertrain components. The linear correlation (5), (Table 3 ) takes into account the price of the parts, as well the manufacturing cost of the vehicle shell. The margin of the carmaker is included as well. A simplified vehicle objective economics function is constructed (7). It takes into account the vehicle powertrain cost (production) (6) and vehicle nominal cost (5).

$$
\begin{aligned}
\operatorname{Cost}_{\text {powertrain }} & =\operatorname{Cost}_{E M}+\operatorname{Cost}_{\text {battery }}+\operatorname{Cost}_{S C}, €, \\
\text { Cost }_{\text {vehicle }} & =\text { Cost }_{\text {powertrain }}+\text { Cost }_{\text {car_shell }}, € .
\end{aligned}
$$

\subsection{Environmental model}

In this work the Life Cycle Assessment is applied as an indicator for the vehicle energy system design. In this study one category from the CML short impact is used. the 100-year Global Warming Potential (GWP). The life cycle of a product, a system or a service has usually three distinct successive phases: the production phase, the use phase and the end-of-life phase. The inventory of the unitary processes and the raw materials for the production of the parts is built from the Eco Invent ${ }^{\circledR}$ database. The vehicle is divided into seven substructures. They allow identifying the powertrain: electric machine, low voltage battery, high voltage battery, power unit, thermal engine, gearbox, vehicle body (car shell). The electric consumption of the vehicle corresponds to the use phase. The inventory for the corresponding electricity production comes from the Eco Invent ${ }^{\circledR}$ database. The end-of-life phase is represented by the average vehicle disposal process. This process also comes from the Eco Invent ${ }^{\circledR}$ database. We consider that the vehicles are operated in France with the French electricity mix. The current normalized driving cycle for characterization of the commercial vehicles is the New European Driving Cycle (NEDC). Table 3 presents the characteristics of the driving cycles used in this study.

Table 3. Drive cycles characteristics.

\begin{tabular}{|c|c|c|c|}
\hline Cycle & Distance, $\mathbf{k m}$ & Duration, $\mathbf{s}$ & Average speed, $\mathbf{k m} / \mathbf{h}$ \\
\hline NEDC & 11,023 & 1180 & 32,26 \\
\hline
\end{tabular}

\section{Results - multi-objective optimization}

\subsection{Problem definition}

A multi-objective optimization is defined for electric vehicles. The environmental category is chosen as optimization function, in addition to the cost and the efficiency. Environomic optimization is researched and evaluated for electric vehicles. Based on the Pareto curves obtained with the results from the multi-objective optimization, optimal vehicle configurations of the cars are discussed and decided.

The environmental impact category (GWP), coming from the life cycle assessment model as performance indicator in the superstructure, is used as an objective function. The variables for the decision are defined in Table 4 . 
Table 4. Decision variables for design - multi-objective optimization problem.

\begin{tabular}{|c|c|c|}
\hline Electric propulsion system components & Range & Unit \\
\hline Electric machine & $15-50$ & $\mathrm{~kW}$ \\
\hline High voltage battery & $10-100$ & $\mathrm{kWh}$ \\
\hline $\begin{array}{c}\text { Number of super capacitors in a parallel } \\
\text { structure }\end{array}$ & $0-5$ & - \\
\hline Max Power of supercapacitors & 87,5 & $\mathrm{~kW}$ \\
\hline
\end{tabular}

\subsection{Multi-objective techno-economic optimization}

The vehicle range is the main technical performance parameter of the electric vehicle. The range depends on the battery capacity on board, and on the energy density of the battery cells.

The cost of the battery is also related to these two parameters and especially to the energy density (equation 3 ). The battery specific energy, which depends on the technology (cathode material, conductivity, etc.), takes considerate time and resources to evolve. The battery capacity can be more easily increased for a given battery type.

In this section a conceptual point-of-view design is adopted by varying the battery specific energy during the two-objective techno-economic optimization. The optimization problem is defined in Table 5.

The techno-economic optimization converges on the Pareto curve presented in Figure 3. The results indicate the effect of the battery specific energy on the autonomy and cost, for current and future battery technologies. The cost and the ranges of the electric vehicle are related to the battery capacity and to the battery density.

The autonomy ranges vary between $100 \mathrm{~km}$ and 500 $\mathrm{km}$. The vehicle cost increases also with the autonomy and the high specific energy. The minimal cost is obtained for batteries with lowest specific energy of $90 \mathrm{Wh} / \mathrm{kg}$. The maximal autonomy of $500 \mathrm{~km}$ is obtained for batteries with $90 \mathrm{kWh}$ of capacity and $400 \mathrm{Wh} / \mathrm{kg}$ of specific energy of the battery cells. Figure 4 presents the evolution of the battery cost as a function of the specific energy for a battery with $20 \mathrm{kWh}$ of capacity. The battery cost varies between $8000 €$ and $42000 €$.

Table 5: Multi-objective optimization objectives and decision variables

\begin{tabular}{|c|c|c|}
\hline \multicolumn{3}{|l|}{ Techno-economic optimization - Objectives } \\
\hline Autonomy & $\mathrm{km}$ & $\mathrm{Max}$ \\
\hline Cost & $€$ & Min \\
\hline $\begin{array}{c}\text { Electric propulsion system } \\
\text { components }\end{array}$ & Range & Unit \\
\hline Electric machine & $15-50$ & $\mathrm{~kW}$ \\
\hline High voltage battery capacity & $10-100$ & $\mathrm{kWh}$ \\
\hline High voltage battery specific energy & $90-400$ & $\mathrm{Wh} / \mathrm{kg}$ \\
\hline $\begin{array}{c}\text { Number of supercapacitors in a parallel } \\
\text { structure }\end{array}$ & $0-5$ & - \\
\hline Max Power of supercapacitors & 87,5 & $\mathrm{~kW}$ \\
\hline
\end{tabular}

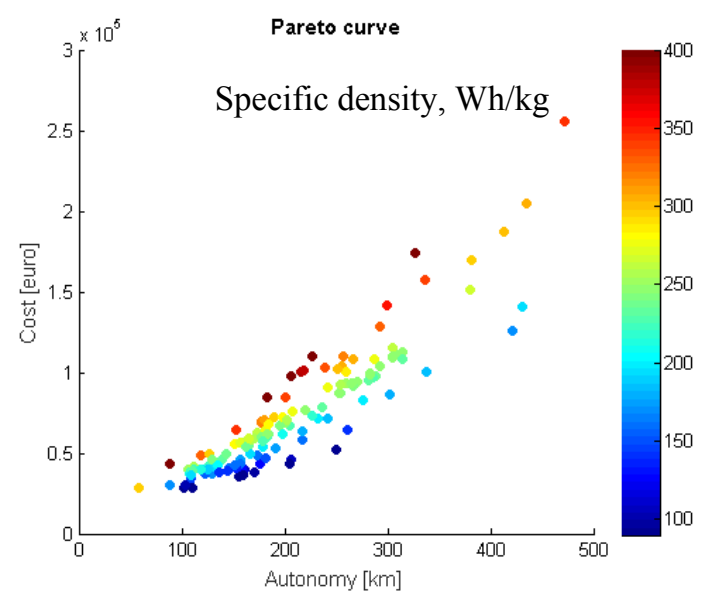

Fig. 3. Pareto for techno-economic optimization, battery specific density in colorbar.

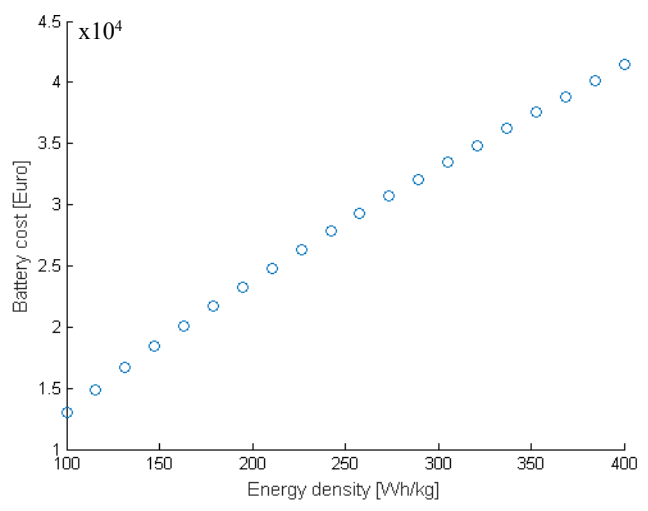

Fig. 4. Evolution of battery cost as a function of battery density, for battery capacity of $20 \mathrm{kWh}$.

The energy capacity of $20 \mathrm{kWh}$ is a reference for the serial electric vehicles and allows for at least $150 \mathrm{~km}$ of autonomy. The autonomy of the electric vehicles needs to be increased and for that purpose the battery capacity on board needs to be increased. Figure 5 presents a simulation of the vehicle range as a function of battery capacity. The simulation is done for the maximal specific energy density of $400 \mathrm{Wh} / \mathrm{kg}$ considered in the study. One can see that a range of $550 \mathrm{~km}$ could be reached with a $100 \mathrm{kWh}$ of battery capacity of the energy board, which is 5 times more that the state-of-the-art of on-board capacities.

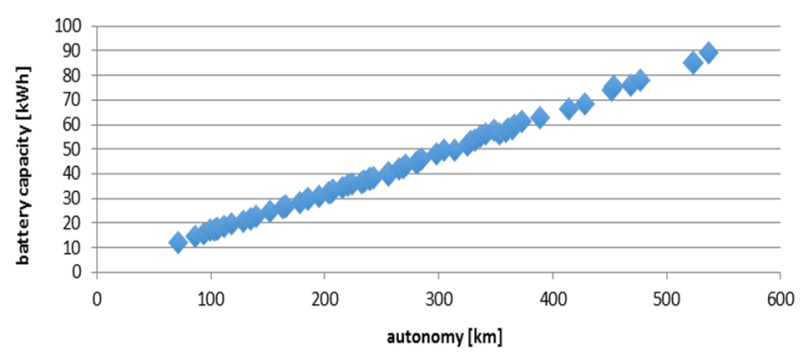

Fig. 5. Evolution of vehicle autonomy as a function of battery capacity, specific energy of $400 \mathrm{Wh} / \mathrm{kg}$.

Ranges higher than $300 \mathrm{~km}$ are important for the development of electric vehicles as a solution for long way mobility. Thus, electric vehicles can be used for holiday drives and not just for home to work urban and 
peri-urban commuting. In addition, the important capacity of $100 \mathrm{kWh}$ sets the question of the vehicle recharging systems and necessitates the development of fast charging systems and their availability on highways.

The time of the recharging of the batteries depends on the battery capacity and also on the power that the recharging infrastructure is capable to deliver. To insure long durability of the battery, the battery optimal use is considered to be for states of the charge between $20 \%$ and $80 \%$ of the maximal capacity. The computation of the time is considered for these boundaries. Table 6 presents the times in minutes for the charging of the batteries with different powers for the chargers. For example, to charge an electric vehicle with $100 \mathrm{kWh}$ of battery with a charger of $50 \mathrm{~kW}$, will take 96 minutes. If the charging is done on the highway, this time is considered to be too long. The charger of $50 \mathrm{~kW}$ can be used in city parking or in shopping centres. An acceptable time for a highway stop is considered to be 15 minutes. To reach this time performance a charger of $350 \mathrm{~kW}$ is needed. Thus, the vehicle with $100 \mathrm{kWh}$ of battery capacity can be charged in 14 minutes.

Table 6. Times of charging of the batteries for different powers of the chargers.

\begin{tabular}{|c|c|c|c|}
\hline Power $(\mathrm{kW})$ & \multicolumn{3}{|c|}{ Time for 80\% state of charge (min) } \\
\hline \multirow{2}{*}{} & $50 \mathrm{kWh}$ & $100 \mathrm{kWh}$ & $150 \mathrm{kWh}$ \\
\cline { 2 - 4 } & 48 & 96 & 144 \\
\hline 50 & 24 & 48 & 72 \\
\hline 100 & 17 & 32 & 51 \\
\hline 350 & 7 & 14 & 21 \\
\hline
\end{tabular}

One can conclude that the long way electric mobility with ranges over $500 \mathrm{~km}$, will develop with increasing battery capacities $(>100 \mathrm{kWh})$ and with the deployment of fast charging infrastructure on highways with chargers capable to deliver at least $350 \mathrm{~kW}$.

\subsection{Multi-objective environomic optimization}

In the environmental model, one can consider the 100year GWP as the main impact category and the GWP is considered as environmental objective to be minimized. The multi-objective problem is defined with 3 objective functions: the autonomy to be maximized, the cost and the GWP impact of the electric vehicles to be minimized. The decision variables are the same ones defined in Table 5.

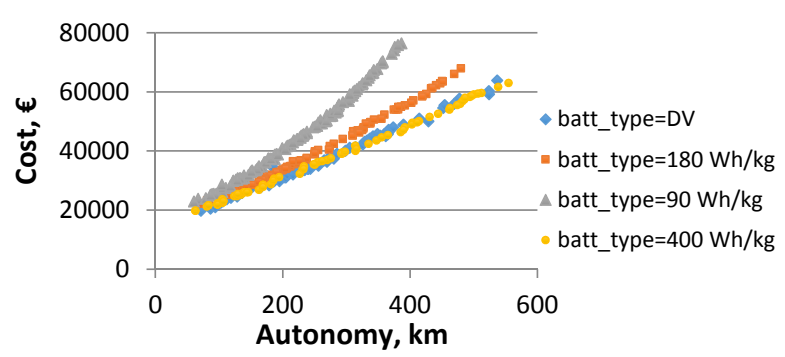

Fig. 6. Pareto of the environomic optimization, 2D plan cost/ autonomy.

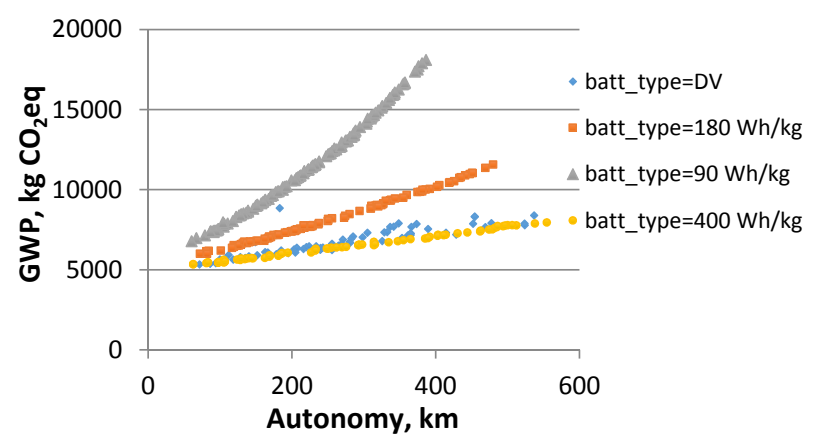

Fig. 7. Pareto of the environomic optimization, 2D plan GWP/ autonomy.

The optimal environomic solutions converge on the Pareto frontiers presented in Figures 6 and 7, as projections in the plans cost/autonomy and GWP/autonomy.

One can see that for battery types with specific efficiency of $90 \mathrm{Wh} / \mathrm{kg}$ the maximal range is estimated at $380 \mathrm{~km}$. For this solution the vehicle cost is estimated to be $76000 €$ and the GWP is estimated to be $18000 \mathrm{~kg} \mathrm{CO}_{2}$ eq. For the battery with specific energy of $180 \mathrm{Wh} / \mathrm{kg}$, the maximal range is $480 \mathrm{~km}$, with a vehicle cost of $68000 €$ and GWP of $12000 \mathrm{~kg} \mathrm{CO} 2$ eq. For the battery with specific energy of $400 \mathrm{Wh} / \mathrm{kg}$, the maximal range is 550 $\mathrm{km}$, with a vehicle cost of $63000 €$ and GWP of $8000 \mathrm{~kg}$ $\mathrm{CO}_{2}$ eq. The first conclusion is that the increase of the specific energy increases the autonomy, but also decreases the battery capacity that is needed to be stored on board. For the value of autonomy of for example 300 $\mathrm{km}$, the cost of the vehicles with $90 \mathrm{Wh} / \mathrm{kg}$ of battery is $58000 €$, the GWP is $14400 \mathrm{~kg} \mathrm{CO}_{2}$ eq. For the same range of $300 \mathrm{~km}$ the cost of the vehicles with $180 \mathrm{Wh} / \mathrm{kg}$ of battery is $44000 €$, the GWP is $8600 \mathrm{~kg} \mathrm{CO}_{2}$ eq. For the range of $300 \mathrm{~km}$ the cost of the vehicles with $400 \mathrm{Wh} / \mathrm{kg}$ of battery is $40000 €$, the GWP is $6500 \mathrm{~kg} \mathrm{CO}_{2}$ eq.

The optimizer chooses the highest specific energy (defined by the upper boundary of the variation range). With the cost model, the slope of the Pareto curve decreases when increasing the specific energy, which explains the choice of the optimizer.

The environomic designs are presented in Table 7 for autonomies of 300 and $550 \mathrm{~km}$.

Table 7. Environomic designs for long range electric vehicles, specific energy of $400 \mathrm{Wh} / \mathrm{kg}$.

\begin{tabular}{|c|c|c|c|}
\hline & Units & ID $=\mathbf{1 7}$ & ID $=\mathbf{7 8}$ \\
\hline Autonomy & $\mathrm{km}$ & 300 & 550 \\
\hline Cost & $€$ & 40000 & 63000 \\
\hline GWP impact & $\mathrm{kg} \mathrm{CO}_{2}$ eq. & 6500 & 8000 \\
\hline Power EM & $\mathrm{kW}$ & 40 & 47 \\
\hline Battery capacity & $\mathrm{kWh}$ & 50 & 90 \\
\hline Specific energy & $\mathrm{Wh} / \mathrm{kg}$ & 400 & 400 \\
\hline Number of supercapacitors & - & 1 & 2 \\
\hline
\end{tabular}




\section{Conclusions}

This paper presents an energy system study of electric vehicles. The study considers different vehicle usages through adapted ranges and referred on the NEDC normalized cycle. The optimal environomic configurations are researched by means of multi-objective optimization. The optimization methodology is based on a genetic algorithm and is applied for defining the optimal set of decision variables for energy system design. The relations between the battery capacity, the battery energy density and the range of the electric vehicles are examined. The designs for different mobility services (urban and long ways distance electric mobility) of the electric vehicles are defined and the time interaction with the charging infrastructure is analysed. Information and connectivity solutions that inform in real time the drivers about the availability and the location of the charging infrastructure, including the possibility to book and pay for charge points in different places, is an important part of the solution. Combined with fast, i.e. high power charging capacities, pure electric vehicles would be able to serve long range needs. The analysis of the environomic Pareto curves on NEDC also illustrates the relation between the economic and the environmental performances of the solutions. Electric vehicles can be used for long way mobility $(>400 \mathrm{~km})$, if they have a consequent capacity of battery on board (between 100 and $150 \mathrm{kWh}$ ). The density of the battery is also important for the autonomy of the electric vehicles. The importance of battery capacity creates the need for high power chargers, which will allow for fast charging of the batteries. The pick power demands induce to investigate adequate links for such electric vehicles with the electricity grid. Multiobjective optimization can be used in an enlarged energy system, including electric vehicles and the electric grid.

\section{Abbreviations}

IVT Electric continuous variable transmission

EV Electric vehicle

GWP Global warming potential

TE Internal combustion engine

$F \quad$ Force, N

$P \quad$ Power, kW

$T \quad$ Torque, $\mathrm{Nm}$

$q_{\text {batt }} \quad$ battery capacity, $\mathrm{kWh}$

w wheels

Subscripts and superscripts

TE thermal engine

SC supercapacitors

\section{References}

1. ERTRAC Report, European road map, electrification of road transport, www.ertrac.org/uploads/ documentsearch/id31/electrification_roadmap_june2 012_62.pdf, accessed on 23.10.2017

2. I. Zenginis, J. S. Vardakas, N. Zorba, Ch. V. Verikoukis, Analysis and quality of service evaluation of a fast charging station for electric vehicles, In Energy, 112, 669-678, (2016)

3. I. Karakitsios, E. Karfopoulos, N. Hatziargyriou, Impact of dynamic and static fast inductive charging of electric vehicles on the distribution network, In Electric Power Systems Research, 140, 107-115, (2016)

4. R. S. Levinson, T. H. West, Impact of public electric vehicle charging infrastructure, Transportation Research Part D: Transport and Environment, Available online 16 October 2017, ISSN 1361-9209, https://doi.org/10.1016/j.trd.2017.10.006.

5. A. Zhang, J. Eun Kang, C. Kwon, Incorporating demand dynamics in multi-period capacitated fastcharging location planning for electric vehicles, In Transportation Research Part B: Methodological, 103, 5-29, (2017)

6. X. Sun, T. Yamamoto, T. Morikawa, Fast-charging station choice behavior among battery electric vehicle users, In Transportation Research Part D: Transport and Environment, 46, 26-39, (2016)

7. F. Wu, R. Sioshansi, A stochastic flow-capturing model to optimize the location of fast-charging stations with uncertain electric vehicle flows, Transportation Research Part D: Transport and Environment, 53, 354-376, (2017)

8. A. Schroeder, T. Traber, The economics of fast charging infrastructure for electric vehicles, In Energy Policy, 43, 136-144, (2012)

9. Z. Dimitrova, F. Maréchal, Environomic design for electric vehicles with an integrated solid oxide fuel cell (SOFC) unit as a range extender, Renewable energy, 112, 124-142, (2017)

10.Z. Dimitrova, Vehicle propulsion systems design methods, MATEC Web of conferences, 133, 02001, (2017)

11. Z. Dimitrova, F. Maréchal, Environomic design of vehicle energy systems for optimal mobility service, Energy Journal, 76, 1019-1028, (2014)

12. Z. Dimitrova, F. Maréchal, Techno-economic design of hybrid electric vehicles, Energy Journal, 91, 630644, (2015) 